\title{
SERVIR HIMALAYA: ENABLING IMPROVED ENVIRONMENTAL MANAGEMENT AND LIVELIHOODS IN THE HKH
}

\author{
B. Bajracharya*, MSR Murthy, B. Shrestha \\ International Centre for Integrated Mountain Development (birendra.bajracharya, manchiraju.murthy, \\ Basanta.shrestha)@icimod.org
}

Commission TC VIII

KEY WORDS: SERVIR, Himalaya, Earth observation, geospatial information, mountain environment

\begin{abstract}
:
With an overarching goal to improve environmental management and resilience to climate change, SERVIR-Himalaya is established as a collaborative initiative of USAID, NASA and ICIMOD. The SERVIR-Himalaya has been the key instrument to provide integrated and innovative geospatial solutions for generation and dissemination of information and knowledge resources on mountain environments. The SERVIR applications, products and services are viewed as essential cross-cutting elements to achieve the greater impacts on addressing Himalayan livelihood challenges. The broad thematic areas which are also subset of the societal benefit areas of Global Earth Observation (GEO), namely - agriculture and food security, ecosystems and sustainable landscapes, and disaster risk management are addressed. On the cross-cutting theme, SERVIR Himalaya is also focusing on developing regional level applications providing key information systems and services on multiple themes of regional significance. The regional level science applications include use of MODIS satellite information products and services for environmental and natural resources monitoring in the Himalayan region. Regional and national training and workshops, on-the-job training, internships and exchange programs and technical backstopping are key capacity building components to enhance the capacity of partners from national institutions in the regional member countries. These efforts are also seen as receiving feedback on the science applications, identify additional needs, and increase synergy by exploring opportunities for collaboration.
\end{abstract}

\section{INTRODUCTION}

\subsection{Mountain perspective and need for Geospatial Framework}

The Hindu Kush-Himalaya (HKH) region is the largest mountain system in the world extending from Myanmar in the East to Afghanistan in the West covering whole or part of Bangladesh, Bhutan, China, India, Nepal, and Pakistan (ICIMOD, 2012). The two specificities of the mountains verticality and variability contribute to their remoteness and highly diverse physical, social, and ecological characteristics (Mountain Forum, 2009). While the region bears special significance in the global ecosystem, it also represents very sensitive social-ecological systems marked by fragility, complexity, and marginality. The HKH region is home to the highest concentration of glaciers and largest storehouse of fresh water outside of the polar region which provide freshwater to 1.3 billion of people in the region and the downstream (ICIMOD, 2012). The impacts of climate change have brought new challenges to the region which was already facing the issues of poverty, environmental degradation, natural resources depletion, shrinking water resources, and desertification. Attributed to climate change, the region has been facing increasing frequency of extreme events and natural disasters which have resulted into losses of lives and properties.

Most of these issues, such as melting glaciers, greenhouse gases, air pollution, biodiversity conservation, and disasters due to extreme events are transboundary in nature which demand collective actions and cooperation between nations. On the other hand, understanding the drivers of change and processes at micro level is equally important due to high variability and diversity. The dynamics of mountain environments needs to be mapped, modelled, monitored, and analysed at multiple-scales to support policy decisions and devising of appropriate development interventions. A common geographic framework provides a basis for integrating multiple disciplines and investigating key components of the social, economic, and environmental conditions to enhance our understanding of the complex mountain ecosystem. The advances in geospatial science and technology supplemented by earth observation information have provided enormous opportunities to overcome the constraints in studies of mountain environments.

One of the major challenges faced by the HKH region is the limited availability of geospatial information. Access to information, data sharing and exchange has been limited due to lack of appropriate regional framework and mechanism. There is also a growing recognition of the need for quality data, and ways of sharing them among stakeholders, to help improve scientific understanding.

\subsection{Global initiatives in support of earth observation applications}

The current decade has seen climate change in the centre stage in global political agenda. Earth observation plays a major role in assessing climate change by providing repetitive and consistent view throughout the globe. Importance of satellite based information to understand earth as a system has been

\footnotetext{
* Corresponding author.
} 
appropriately recognized by the global scientific communities and we have observed a number of initiatives to facilitate and promote their applications. The Global Climate Observation System (GCOS) provides for comprehensive observations for research and for detecting and attributing climate change to support the United Nations Framework Convention on Climate Change (UNFCCC) through harmonized national observation systems to avoid both gaps and redundancies in Earth observation programs (Lewis et al 2010). GCOS works towards ensuring free and unrestricted availability of climate and related data for informed decision making. The Committee on Earth Observation Satellites (CEOS), is another principal body for coordinating Earth observation among national civil space programs. It also supports the Group on Earth Observation (GEO), an operational body established in 2005 to provide "a single, comprehensive and sustained system for Earth Observation." GEO, with a permanent secretariat in Geneva, is a voluntary partnership of governments and international organizations that provides a framework for coordinated strategies and investments (GEO 2013). GEO is the body that coordinates and sets up the architecture for the "system of systems" (GEOSS) to ensure complete coverage and compatibility of data. It is a high-level (ministerial) forum for all nations and UN/intergovernmental organizations that contribute or use Earth observation data to work out the details involved in ensuring that systems are compatible and data are available across the globe.

\subsection{Paradigm shift in geospatial communities and practice}

NASA and USGS made the Landsat images free which has greatly encouraged the use of these data by the researchers. Since the entire Landsat archive became available to all users at no charge in December 2008, over 19 million scenes have been downloaded till August 2014 (USGS 2014). Another encouraging step was announce by the White House on September 23th during the United Nations Heads of State Climate Summit in New York that they are going to release the high-resolution $(30 \mathrm{mx} 30 \mathrm{~m})$ images of SRTM globally. Until now, the high-resolution imagery were only available for USareas. This is expected to enhance the spatial analysis in the mountain terrains.

The launching of Google Earth in 2005 has revolutionized the way people use Geographic information. Browsing digital geographic information over the web (geobrowsing) has led to development of innovative applications to explore data geographically, and visualise overlaid information provided by diverse contributors. Integration of geobrowsers such as Google Earth and Google Map through application programming interfaces (APIs) has popularized the use of map for serving all sorts of information. Similarly, introduction of smartphones with map based applications and GPS has brought GIS into fingertips of common people. With the mobile phones getting more affordable, the mobile-density has reached over 70 percent in the $\mathrm{HKH}$ region.

The more open policies on earth observation and wider access and affordability of consumer products enabling use of spatial information has brought in new paradigm in GIS application development and use. These developments at global and national levels have opened enormous opportunities in studies of mountain environments.

\section{SERVIR INITIATIVE}

\subsection{SERVIR-Himalaya connecting space to village}

SERVIR is a regional visualisation and monitoring system that integrates earth observations such as satellite imagery and forecast models together with in situ data and other knowledge for timely decision-making. SERVIR evolved through a 'nontraditional' partnership between USAID (United States Agency for International Development) and NASA (National Aeronautics and Space Administration) to make earth observation data, decision-support tools for interpreting the data, and online mapping capability, more generally available. SERVIR places a strong emphasis on partnerships to fortify the access to and availability of earth observations, spatial analysis, and visualisation.

The first SERVIR regional operational facility - for the Latin America and the Caribbean region - was established in 2005 through the efforts of National Aeronautics Space Agency (NASA), United States Agency for International Development (USAID), the Water Center for the Humid Tropics of Latin America and the Caribbean (CATHALAC), the Central American Commission for the Environment and Development (CCAD), and other partners, at the request of the governments of Central America, as an innovative way to utilize space based assets for development. A second SERVIR regional operational facility - for East Africa - was initiated in 2008 at the Regional Center for Mapping of Resources for Development (RCMRD) in Nairobi, Kenya. SERVIR-Himalaya was initiated in late 2010 with ICIMOD, with its focus in the Hindu Kush Himalaya region. SERVIR Himalaya is implemented through ICIMODs regional program Mountain Environment Regional Information System (MENRIS). Very recently, a new hub SERVIR Lower Mekong has been formally launched in November this year

The overarching purpose of the SERVIR-Himalaya initiative is to improve environmental decision-making in the Hindu KushHimalayan region through dissemination and analysis of earth observation information. Stakeholders for this kind of information range from decision-makers at the regional level addressing transboundary issues, to national governments, scientists, students, the general public, donors, and development practitioners.

\subsection{Priority areas and themes}

Driven by the SERVIR's motto 'Connecting Space to Village', SERVIR-Himalaya works as a regional resource centre in the Hindu Kush Himalayan region. The activities of SERVIRHimalaya are designed from the perspective of Supply (tools, technologies and methods offered by the available Earth observation and Geospatial information systems) and Demand (information gaps, user needs, and creating enabling environments).

Based on the findings of series of needs assessment workshops and also considering ICIMOD's priority areas and GEO societal benefit areas, SERVIR Himalaya has focused on the broader themes of Agriculture and food security, Ecosystems, Cryosphere, Disaster, Air quality. For each of these themes, assessment of major issues, key stakeholders in the countries, on-going initiatives, gaps and opportunities were carried out. 
Under the Supply component, a number of Science applications are being implemented. These include development of methodologies and innovative applications of Earth observation data in the above thematic areas, and development of customized information systems and web based tools. Decision support tools are developed by integrating these methodologies, query and interactive visualization tools for easy use by the target audience.

The Demand component includes creating enabling environments through capacity building, creating platforms for access and sharing of data, and wider engagement of users beyond the scientific communities during the process of development and dissemination of SERVIR applications.

\subsection{Science applications - addressing the regional and national needs}

Science applications are designed to address the gaps and needs identified in the national and regional context. Some of the ongoing applications are presented here.

\subsubsection{Satellite based Agriculture Drought Warning System}

Over the last few decades the HKH region is experiencing high degree of spatial and temporal climate variability affecting crop production. SERVIR Himalaya is developing satellite based agriculture drought monitoring system to support sub-district level planners and decision makers in Nepal. Over the last year, the crop calendars, crop intensity and area under major crops like rice, wheat and maize are delineated using multi temporal Moderate Resolution Imaging Spectroradiometer (MODIS) satellite data of $250 \mathrm{~m}$ resolution. The crop phenology patterns over the last decade was analysed using fortnightly MODIS $250 \mathrm{~m}$ satellite data. Using this decadal response patterns as a base, fortnightly Normalised Difference Vegetation Index (NDVI) based in season crop growth anomaly maps are generated. Integration of information on seasonal vegetation performance and climate-based drought indicators are used to produce a timely and spatially-detailed drought monitoring information products. Additional datasets (e.g. historical climate and crop production patterns, real-time field based climate and crop data, knowledge of cropping practice, satellite based Moisture based Vegetation Index, Land Surface Temperature (LST), CHIRPS Rainfall data) are being integrated into the system using empirical modeling approaches.

\subsubsection{Rangelands Decision Support System in the HKH Region of Pakistan}

As part of the agro-pastoral ecosystem, rangelands cover a large and contiguous part of the HKH region. Properly managed rangelands can enhance food security and poverty alleviation to millions of people living in the mountain regions. Understanding the dynamics of rangelands and thereby the sustainable management of complex pastoral systems is needed to utilize these resources in harmony with nature. The present application intends to develop operational mechanism to provide in season dynamics of rangeland growth over Pakistan and pilot study over selected parts to develop decision support tools for optimized grazing plans. The study builds on capacity being built to produce regional MODIS based products and the extensive studies being carried out by ICIMOD on rangeland calendars, long term rangeland responses to climate and field studies on socio economic structures.
2.3.3 Biomass estimation using multi-resolution satellite data at sub-national level

Agriculture, Forest and Other Land Use (AFOLU) system offers a critical basis for creating and safeguarding more climate-resilient communities in the HKH region. This has called for reliable baseline assessment of forest biomass and its monitoring strategies at multiple scales to ensure optimal supply - demand resource scenario and also leverage carbon mitigation benefits through mechanisms like Clean Development Mechanism(CDM) and REDD+. The work includes estimation of biomass using multi resolution satellite data and ground information at watershed level which are upscaled over to districts levels. A web enabled monitoring system to support mechanisms liked REDD Monitoring, reporting and verification (MRV) is being developed using open source platform.

2.3.4 Multi-scale disaster risk assessment and decision support system for DRR

Disaster risk reduction (DRR) efforts needs understanding both as combined effects of multiple disasters and also at individual disaster. However the requirement of degree and type of understanding varies as a function of scale at which DRR management options are operated. A framework consisting of broad information on multiple disasters at national level and detailed information on specific disasters at vulnerable zones would help better preparedness towards disaster risk management. A multilevel hazard and risk analysis system is being developed will through wider stakeholder consultation. A decision support system is also being developed by integrating the data and information to aid in decision making for managing flood hazard and associated risk in Nepal.

\subsubsection{Forest Fire Detection \& Monitoring}

Forest fire is a big concern in many countries including Nepal and Bhutan due to its adverse ecological and economic effects. A need for reliable and time effective information on fire is realized to be important as part of forest fire management. In view of its synoptic and high repetitive coverage, satellite data is found quite useful in fire detection and monitoring, and burnt area assessment on near real time basis. MODIS sensor on board Terra and Aqua satellites of NASA is extensively used for the purpose across the globe. SERVIR Himalaya has developed SERVIR Himalaya has developed a forest fire detection and monitoring system for Nepal and Bhutan based on MODIS data. The work was carried out in close collaboration with the Department of Forest in both countries. The system carries out automated data acquisition, processing, reporting, and feedback on fire location. It provides location information on active fires present during the satellite's twice-daily overpasses. The system automatically adds important information to these data such as administrative unit (i.e., district/dzongkhag, VDC/gewog, etc.), protected area identification, land cover type, elevation, and slope. The system then sends email notifications and sms text about active fires to the subscribers which includes district forest officers, park managers and other relevant stakeholders. In addition, an interactive mapping application allows visualization of active fire locations on any given day along with district level fire count statistics. 
2.3.5 MODIS ground station implementation and regional product development

Understanding of long-term ecosystem response over the HKH region is critical for adaptation strategies. Operational satellite based near real-time ecosystem monitoring system provides primary scientific framework for furthering knowledge development and decision making by bridging the prevailing data and information gaps. Currently long-term ecosystem understanding to climate patterns and continuous monitoring systems which can support suitable conservation and adaptation strategies are lacking in the region. High temporal satellite products like MODIS should be made more customized to HKH system and user friendly dissemination and visualization are needed to support knowledge development and decision making. SERVIR Himalaya is focusing to strengthen real time product delivery, provide Pull-Push data services and improved Level-III products and alerts in terms of calibration and customization to regional context.

\section{SCALES OF OPERATION}

The remote sensing and the satellites give us the eagle-eye view which is essential but not enough. The eagle-eye view needs to be complemented by the view from the ground or the "toad'seye" view (Hilton et. al, 2009). SERVIR's vision of "Connecting space to Village" demands to interface between the technological advancements at global front and the issues and needs at local community levels. Considering the nature of the issues, the science applications are designed at different scales. Applications such as long term ecosystem monitoring, snow cover mapping and transboundary air quality are looking at the regional scale covering the whole $\mathrm{HKH}$ region.

The applications on rangeland and agriculture are focusing at country level. Similarly the forest fire application is implemented at national scales since the management procedure are country specific. The above biomass estimation is looking at the watershed level which is now up-scaled at district and national levels. At the watershed level, the primary target group is Community Forestry User Groups while at the national level the line ministry and departments are the primary users.

Another important aspect is to look at the temporal resolution. The forest fire application provides data four times a day. Snow cover data is updated every week while information on agriculture and rangeland is carried out fortnightly. Information on forest biomass, land cover, glaciers are updated over a year to five year period. The temporal resolution is dictated by frequency of satellite data and the variability of the theme.

\section{TECHNOLOGY ADOPTION}

\subsection{Reaching the communities}

Strengthening national and regional capacity to enable the use of earth observation information and geospatial tools for developmental decision-making is the major focus of SERVIRHimalaya. There is a need to increase awareness and extend SERVIR benefits to ministries and/or national agencies for sustainable use of SERVIR's products and services and foster data sharing and exchange among the multi-sectoral agencies.
In this regard, SERVIR has been carrying out various capacity building activities and developing national geospatial portals.

All the science applications and related data are made accessible to the users through ICIMOD's Mountain Geoportal. Users can use the web based tools for interactive query and visualization of information in different application areas. Metadata of all the data are also made available through quick and advanced search tools for easy access.

\subsubsection{Capacity building}

SERVIR-Himalaya conducts customized trainings on its science applications targeted the relevant institutions in the regional countries. The trainings are organized as regional and national trainings which are focused to participants from different government and non-government agencies, universities and academic institutions. Focused opportunities are provided through on-the-job training to relevant institutions for in-depth skills developed in specific applications.

SERVIR Himalaya has been regularly organizing Youth Forum targeting the fresh graduates and young professionals to increase awareness on earth observation application to climate change issues. In collaboration with NASA Develop program, SERVIR Himalaya provides internships to the students from the region.

\subsubsection{National Geospatial Portals}

One of the major challenges facing the HKH region today is the limited availability and sharing of geo-information. SERVIRHimalaya is consolidating its efforts in Bhutan and Nepal to provide geospatial information services by developing national Geospatial Portals. The Bhutan Geospatial Portal was launched in October this year. National Geospatial Portals are implemented for coordinated development and delivery of national geospatial services for improved decision-making. These efforts are also seen as a catalytic in complementing national SDI components by building synergies with relevant national programs and initiatives to facilitate data standardization, sharing and exchange. Geospatial Portals from SERVIR will be one-of-its-kind in those member countries and are expected to help foster collaboration and synergy with other similar initiatives. Ultimately it will help create ownership and grow geospatial information services in Bhutan and Nepal.

\section{CONCLUSION}

Over the past decade, ICIMOD, together with national and international partners, has promoted the use of GIS and earth observation applications at multiple scales to support its mission and strategic priorities. These regional priorities are closely interlinked and interdependent, and improved understanding of the interrelationships between different components is a key challenge. Reliable and timely information on environment and society is critical for such improved understanding of the status, changes and inter-linkages.

The emerging initiatives at the global, regional and national fronts and advancements in geospatial technologies has greatly changed the scenario in the user landscape. The easy access to spatial information through mobile devices has mainstreamed the use of spatial information by the common people and has 
given birth to many applications that are useful in daily life. The new concepts such as GeoDesign to bring geographic analysis into the design process where initial design sketches are instantly vetted for suitability against a myriad of database layers describing a variety of physical and social factors for the spatial extent has opened up enormous opportunities for application developers and decision makers (ESRI 2010). The mobile technologies has also made it possible for materializing the concepts of Citizen Science where the systematic collection and analysis of data and development of technologies are done through public participation.

ICIMOD through its SERVIR Himalaya initiative is striving towards benefiting from these opportunities to make real difference to the people in the HKH. The science applications, trainings and user engagements at various levels are targeted to develop enabling environment in the region where spatial information on all the issues are available to the users and decisions are made on the basis of these analyses.

\section{REFERENCE}

ESRI (2010) Changing Geography by Design, Environment Systems Research Institute

GEO (2013) Report on Progress 2011-2013, Geneva Ministerial Summit, Group on Earth Observation

Hilton, Isabel, Andreas Schild, Mohan Munasinghe, and Dipak Gyawali, "Regional Cooperation at the Third Pole: The Himalayan-Tibetan Plateau and Climate Change," The Asia-Pacific Journal, Vol. 38-2-09, September 21, 2009. http://www.japanfocus.org/-Dipak-Gyawali/3224

ICIMOD (2012) A Strategy and Results Framework for ICIMOD, International Centre for Integrated Mountain Development.

Lewis, James A., Sarah O. Ladislaw, Denise E. Zheng (2010) Earth Observation for Climate Change - A Report of the CSIS Technology and Public Policy Program, Center for Strategic and International Studies (CSIS).

Mountain Forum (2009) Mountain GIS: Promoting Geographic Information and Earth Observation Applications for the Sustainable Development of the Hindu Kush-Himalayan Region, E-conference Report, Mountain Forum Secretariat and International Centre for Integrated Mountain Development.

USGS (2014) Landsat Project Statistics - As of August 7, 2014 http://landsat.usgs.gov/Landsat_Project_Statistics.php 